\section{The mathematics of thermal sub-optimality: Nonlinear regression characterization of thermal performance of reptile metabolic rates.}

Sean Tomlinson ${ }^{1,2}$

${ }^{1}$ School of Molecular and Life Sciences, Curtin University, Kent Street, Bentley 6102 Western

Australia

${ }^{2}$ Kings Park Science, Department of Biodiversity, Conservation and Attractions, Kattidj Close, Kings Park 6005, Western Australia

*Author for correspondence: sean.tomlinson@dbca.wa.gov.au

Running Head: Non-linear Regression Estimates of Ectotherm Optimality

Keywords: thermal performance, metabolic rate, non-linear regression, ectotherm, reptile, Agamidae, Iguanidae, Scincidae

The thermal performance of ectotherms is characterised as unimodal and asymmetrical. Although still debated, it has been assumed that the peak of a performance curve indicates the optimal temperature for an organism. The temperature at this peak rarely coincides with preferred body temperatures, suggesting that the assumption is unsound. Any mathematical formulation hoping to characterise the thermal performance of ectotherms must accommodate the disagreement between the peak of the performance function and the preferred temperature of the target organism(s). The mathematical function examined and advocated here provides the most intuitive equation to describe thermal performance by ectotherms. It also quantifies several physiologically informative parameters, one of which seems congruent with preferred body temperatures. 
Although several approaches have been suggested, there is no broadly accepted single approach for quantitative characterization of thermal performance in ectotherms. I sought to identify the most appropriate non-linear function with which to represent thermal performance of ectothermic metabolic rate, and to interrogate the biological relevance of the thermal parameters of this function. I used published data for exercise-induced metabolic rates of nine species of reptile from a broad phylogenetic base and global distribution. Using an Akaike Information Criterion, I compared 12 different models proposed to characterize thermal performance adapted from a broad range of disciplines, finding that a beta-distribution model described the reptile metabolic rate data most parsimoniously. Using the beta-distribution model, unique functions were parameterized for each species. Four parameters were extracted from each species-specific fit: the temperature coincident with the peak of the thermal performance curve, $T_{\text {opt }}$; the point at which the function intersected the $\mathrm{x}$-axis, $\mathrm{CT}_{\max }$; and two points indicative of thermal breadth, $T_{d(\text { (lower) }}$ and $T_{d(\text { upper). }}$. There was a positive relationship between the species' preferred body temperatures ( $T_{\text {pref }}$ ) reported in the scientific literature and both $T_{\text {opt }}$ and $T_{d(\text { lower) }}$ extracted from the species-specific beta functions. While $T_{d(\text { lower) }}$ estimates were not different to published $T_{\text {pref }}$ values, $T_{\text {opt }}$ estimates were statistically higher than $T_{\text {pref. }}$ This is consistent with previous observations that the point of peak performance does not match $\mathrm{T}_{\text {pref. }}$. The predicted $\mathrm{CT}_{\max }$ also correlated well with published values. The model in its current form was not able to estimate $\mathrm{CT}_{\min }$, and this parameter was not explored here, but should be in future research. By providing a quantitative description of the thermal performance, the beta-distribution function offers a new theoretical basis for thermal optimality. I contend that $T_{\text {pref }}$ aligns with the mathematical threshold $T_{d(\text { lower), }}$ where metabolic rate is at its maximum prior to thermal inhibition. 
Introduction

64

65

Temperature is one of the most ubiquitous abiotic factors encountered by organisms (Withers, 1992), and the influence that it has upon their performance is a critical determinant of fitness (Somero, 2005). Since thermal performance is critical in both driving and constraining many aspects of ecology and evolution (Somero, 2005; Dowd et al., 2015), attempts to quantify its optimum have been incorporated into many contributions to conservation, environmental management, and pure biological research (e.g. Buckley (2008); Kearney et al. (2009); Evans et al. (2015); Tuff et al. (2016)). The basis of all of these applications is that there should be an optimal temperature at which performance is maximized while accruing minimal deleterious effects such as oxidative damage. Beyond this threshold performance declines rapidly (Angilletta, 2006). This thermal optimum, $T_{\text {opt, }}$ might be intuitively expected to occur at the peak of the thermal performance curve (Huey \& Kingsolver, 1989; Martin \& Huey, 2008; Dowd et al., 2015). However, accumulating evidence indicates that preferred body temperatures, $T_{\text {pref, }}$ of many ectotherms do not and should not coincide with the hypothesized Topt (Martin \& Huey, 2008).

The diverse array of potential performance metrics includes, among a great many others, sprint speed, juvenile development rates (both in invertebrates and vertebrates), and respiration patterns (Angilletta, 2009). Underpinning many of these measures is the constraint imposed by the effects of temperature on enzymatic reactions (Huey \& Kingsolver, 1989), or oxygen limitation on mitochondrial activity (Pörtner, 2010). There is a long heritage of seeking phylogenetic and ecological signals in the average metabolic rates of species as well (Andrews \& Pough, 1985; Lighton \& Fielden, 1995; Chown et al., 2007). Furthermore, the involvement of metabolic rates in thermal performance has gained increasing recognition in the last decade (Angilletta, 2009; Pörtner, 2010). Yet, while there is much empirical evidence for the characteristic asymmetrical, unimodal curve describing a number of performance metrics (Angilletta (2006); Figure 1) from sprint speed to fecundity to metabolic rates, there has been no broadly accepted analysis that provides consistent interpretation of these curves between species (Dowd et al., 2015). Here I have investigated various potential models of 
thermal performance using exercise-induced peak metabolic rates of reptiles, and following the assumption that patterns in metabolic rates should be broadly indicative of the patterns of most performance metrics (Gillooly et al., 2001; Gillooly et al., 2002) at least insofar as they are measured for whole animals, rather than isolated enzyme-catalysed reactions (Huey, 1982).

Understanding thermal performance of metabolic rates in ectotherms has long been of interest to comparative physiologists and ecophysiologists. However, unlike the study of endotherms for which Scholander et al. (1953) provides a unifying theoretical construct, a consistent theoretical model for ectotherms has been lacking (Angilletta, 2006), despite many attempts in the last half century (Thornton \& Lessem, 1978; Wollkind et al., 1978; Hertz et al., 1983; Crowley, 1985; Kovac et al., 2007; Tomlinson \& Menz, 2015; Tomlinson \& Phillips, 2015). The lack of a broadly agreed arithmetic model describing thermal performance in ectotherms (analogous to the Scholander-Irving model) has generated a great deal of debate concerning the ecological and evolutionary bases to thermal sensitivity in ectotherms (Huey \& Kingsolver, 1989; Gilchrist, 1995; Angilletta et al., 2003; Angilletta, 2009). From this debate, two consistent elements have emerged that require synthesis: (a) there is expected to be a continuous, non-linear increase in performance related to increased chemical kinetics (Huey \& Stevenson, 1979; Huey \& Kingsolver, 1989; Angilletta, 2009) to (b) a point where thermal limitation is either imposed by increased mitochondrial inefficiency (Pörtner et al., 2006), by enzyme denaturation (Somero, 2002) or several other potential physiological constraints (Somero, 2002). This schema establishes how thermal increase and inhibition accelerate chemical reaction rates, leading to the Arrhenius model of thermal performance (Sharpe \& DeMichele, 1977), but offers little insight into an appropriate mathematical function to characterize the physiological performance more broadly, including any intrinsic interspecific differences in the performance traits themselves.

Additional to the thermokinetic aspects above, I contend that there must be both minimum and maximum asymptotes to the function. The minimum asymptote must be zero or more because performance of any type, including metabolic rate, cannot be negative. The existence of the upper asymptote is less well-articulated in ectotherms, although it is a common concept for endotherms (Tomlinson, 2016). My reasoning for its existence in relation to ectothermic metabolic rate is that the supply networks required to fuel metabolic activity 
must impose some structural limitations to maximum performance. These could be anything from oxygen supply limitation leading to mitochondrial inefficiency (sensu (Pörtner, 2010)), limitations in the production and transport of ATP within the cell (Suarez, 1996), or any number of other biophysical mechanisms. Pörtner (2001) presents relatively strong evidence for aquatic ectotherms and there has been some tentative suggestion for terrestrial species (Pörtner, 2001; Tomlinson et al., 2017) that, when an ectotherm approaches thermal maxima, as its energetic expenditure peaks, it may no longer have any capacity to supply the oxygen requirements for activity (Pörtner, 2001; Pörtner, 2010). Regardless of the specific mechanism(s) at play, their ultimate outcome would be an upper limit where metabolic rate is not thermally constrained, but is operating at the peak structural capacity of the animal. Represented graphically (Figure 1), these four elements imply that below the critical temperature where thermal inhibition takes place, the thermal performance of metabolic rate is S-shaped. This might traditionally imply that thermal performance is a logistic function, characterized by a lower asymptote $\left(r_{\min }\right)$, an upper asymptote $\left(r_{\max }\right)$, a nonlinear "slope", or exponential scaling factor $b$, and a midpoint $\left(T_{i}\right)$, representing $50 \%$ of $r_{\text {max }}$, around which the thermal function is symmetrical (Ritz \& Streibig, 2008). Finally, the rapid, non-linear decline in performance above a critical threshold (Angilletta, 2006), while an essential element of the model, can be captured arithmetically in a number of ways. Models encapsulating these theoretical constraints have previously been proposed to describe thermal performance by ectotherms (Hertz, 1983; Crowley, 1985; Kovac et al., 2007); however, there are other, structurally simpler thermal performance models in the broader literature that serve similar purposes (Yan \& Hunt, 1999; Arnall et al., 2014; Tomlinson et al., 2015; Tomlinson \& Phillips, 2015).

Fitting non-linear functions to thermal performance provides the mathematical basis to such a theory, where the majority of parameters represent physiological responses of the organism and interspecific differences can then be interpreted consistently. Traditionally, where thermal performance of metabolic rates has been statistically modelled at all, it has been interrogated by linearizing the data through mathematical transformation and fitting segmented regressions to it (e.g. Bennett and Dawson (1972); Snyder and Weathers (1976); 
data, reducing the number of parameters required to describe any patterns, but they also alter the variance structure (Hayes \& Shonkwiler, 2006; Gurka \& Edwards, 2011), generally compressing it and constraining the interpretation of potentially adaptive traits. More realistically, these relationships should be analyzed by the application of nonlinear functions in order to maintain as many physiologically informative factors as possible. My objective here was to identify the most appropriate, broadly applicable theoretical model of thermal performance of metabolic rate in ectotherms by resolving the most appropriate of the proposed non-linear functions, using a meta-data set of reptile metabolic rates. I also aimed to see whether the most appropriate model of thermal performance was capable of estimating preferred body temperatures, $\mathrm{T}_{\text {pref, }}$ by correlating known preferred body temperatures of my nine study species with the modelled temperature thresholds derived from the species-specific functions.

\section{Methods}

\section{Study taxa}

This study required a solid database of standardized metabolic rates of ectothermic taxa to be coupled with reliable estimates of their preferred body temperatures $\left(T_{\text {pref }}\right)$. While metabolic rates have been studied in a great diversity of ectotherms, there are several decades of studies specifically focusing on reptiles, and their thermoregulation and thermal preferences (Martin \& Huey, 2008). Few of these studies, however, have managed to capture a breadth of thermal performance suitable for fitting the non-linear functions that I explored here. Thus, the data that I have garnered from the literature represent the small number of papers where the exercise-induced maximal metabolic rates (MMR) of active squamate reptiles increase with $T_{b}$ and show a decrease beyond their peak capacity. This data set encompasses only eight species of reptiles from three families, including the Agamidae (Wilson, 1974), Iguanidae (Moberly, 1968; Bennett, 1972; Bennett \& Dawson, 1972; Bennett et al., 1975), and Scincidae (Wilson, 1974) (Table 1). 
Raw data of individual responses were extracted by calculating Cartesian co-ordinates of the published figures and converting these to independent data points. For the purposes of comparison, all metabolic data were allometrically standardized to $\mathrm{mLO}_{2} \cdot \mathrm{g}^{-0.80} \cdot \mathrm{h}^{-1}$ (Andrews \& Pough, 1985). Given that individual masses were rarely available, all mass corrections were undertaken using the published mean values for the species. Since the data used for the analyses herein do not perfectly represent the values published for each species, the individual data are included in Appendix 1.

\section{Statistical analysis}

(Huey, 1982) characterised models of thermal performance as falling into three categories: empirical, descriptive, and deductive, noting that, while performance data would ideally be fitted to a theoretical function derived from an underlying set of physical principles, the only deductive curves available were based upon chemical reactions, and were far removed from whole-animal physiology. In a similar manner, three of the functions that I identified for my candidate library have been derived from chemical kinetics. The first model was a multiexponential model, first developed by Sharpe and DeMichele (1977) to characterize the relationship between temperature and the development rates of insects based upon Arrhenius laws of chemical kinetics. This has been reformulated for application to metabolic rates (Kooijman, 2010), and used to characterize the thermal performance of at least one reptile (Arnall et al., 2014) in the form:

$$
\dot{\mathrm{V}} \mathrm{O}_{2}=\frac{\exp ^{\left(\frac{T_{A}}{\mathrm{~T}_{\mathrm{R}}}-\frac{T_{A}}{\mathrm{~T}_{\mathrm{b}}}\right)}}{1+\exp { }^{\left(\frac{T_{A L}}{\mathrm{~T}_{\mathrm{b}}}-\frac{T_{A L}}{T_{L}}\right)}+\exp { }^{\left(\frac{T_{A H}}{T_{H}}-\frac{T_{A H}}{T_{\mathrm{b}}}\right)}}
$$

where $T_{R}$ represents a reference temperature, $T_{L}$ and $T_{H}$ represent the lower and upper thermal tolerance limits respectively. Distinct from earlier iterations constructed around activation energy and enthalpy of specific reactions (Sharpe \& DeMichele, 1977; Schoolfield et al., 1981), the reformulation makes use of "Arrhenius temperatures", described as "the 
absolute temperature" (Kooijman, 2010). While these parameters have the dimension of temperature $(K)$, this is presumably an energetic equivalent value to standardize the units of the function. I this context, Kooijman (2010) characterizes $T_{A}$ to represent the Arrhenius temperature of the reaction within the tolerance thresholds, and $T_{A L}$ and $T_{A H}$ are the Arrhenius temperatures for the rate of decrease beyond these thresholds.

A second function derived from chemical kinetics was proposed by Johnson et al. (1954) on the basis of enzyme activation:

$$
\dot{\mathrm{V}} \mathrm{O}_{2}=\frac{c \times T_{b} \times \exp ^{-\frac{\Delta H^{\ddagger}}{R \times T_{b}}}}{1+\exp ^{-\frac{\Delta H_{1}}{R \times T_{b}}} \times \exp \frac{\Delta S_{1}}{R}}
$$

Where $\Delta H^{\ddagger}$ represents the heat activation for transition state intermediates $\Delta H_{1}$ represents the heat activation for the reaction (in this case respiration), $\Delta S_{1}$ represents the entropy of the reaction (in this case respiration), $R$ represents the gas law constant ( 8.31) and $c$ represents a constant. Consistent with this interest in chemical kinetics mediated by enzyme thermal tolerance, Ratkowsky et al. (2005) proposed the third function in my candidate set:

$$
\dot{\mathrm{V}} \mathrm{O}_{2}=\frac{c_{T} \times \exp ^{\frac{-\Delta H^{\ddagger}}{R \times T_{b}}}}{1+\exp \frac{-n \times\left(\Delta H_{1}-18.1 \times T_{b}+\Delta C_{P}\right) \times\left(\left(T_{b}-373.6\right)-T_{b} \times \ln \left(\frac{T_{b}}{385.2}\right)\right)}{R \times T_{b}}}
$$

Where additional parameters included are the heat capacity change between the native and denatured states of the controlling enzyme $\left(\Delta C_{P}\right)$, the enthalpy change at the convergence temperature for enthalpy $\left(\Delta H_{1}\right)$, and the number of amino acid residues in the protein $(n)$.

The functions described above notably don't parameterize variables that are informative to whole animal physiology (Huey, 1982), namely minimum performance, maximum performance, the temperature of peak performance (the canonical $T_{o p t}$ ), nor any suggestion of $T_{\text {pref. }}$. Functions of that do describe these parameters fall into the empirical and descriptive categories of functions identified by Huey (1982), which were distinguished on the basis of their mathematical origin (empirical) and their use of specific physiological parameters (descriptive). I draw no distinction between the two categories here, but included in my candidate library eight published functions which specifically incorporate species-specific 
performance traits such as the upper asymptotes (parameterized here as $r_{\text {max }}$ ) and/or lower asymptotes $\left(r_{\min }\right)$, and physiologically informative temperature thresholds such as $T_{\text {opt }}, C T_{\max }$ (the point where performance equals zero), $T_{l}$ (the lower critical temperatures), $T_{u}$ (the upper critical temperature) into the equations. These functions also typically include some form of reaction rate multiplier, $k$. For purposes of comparison, I have re-parameterized these from their original forms such that all the equivalent parameters are represented by consistent cyphers here.

The first of these physiologically informed functions I re-parameterized from a skewed normal function (Lehman et al., 1975) that originally incorporated temperature thresholds and a constant, $c$, that defined the breadth of the curve (originally enumerated as -2.3; Lehman et al. (1975)), but not performance asymptotes. In order to translate this to represent metabolic rates, the upper asymptote $r_{\max }$ had to be introduced, and the "sign" function (sgn) employed to mathematically articulate the piece-wise nature of the original algorithm:

$$
\dot{\mathrm{V}} \mathrm{O}_{2}=r_{\text {max }} \times \exp ^{c \times\left(\frac{T_{b}-T_{o p t}}{T_{l}-T_{o p t}} \times \frac{T_{b}-T_{o p t}}{T_{u}-T_{o p t}}\right)}
$$

The fifth of my candidate thermal performance function was a special Poisson-density function (O'Neill et al., 1972):

$$
\begin{gathered}
\dot{\mathrm{V}} \mathrm{O}_{2}=r_{\text {max }} \times\left(\frac{C T_{\text {max }}-T_{b}}{C T_{\text {max }}-T_{\text {opt }}}\right) \frac{\left(\ln \left(Q_{10}\right) \times\left(C T_{\text {max }}-T_{\text {opt }}\right)\right)^{2} \times\left(1+\sqrt{1}+\frac{40}{\left(\ln \left(Q_{10}\right) \times\left(C T_{\text {max }}-T_{\text {opt }}+2\right)\right)}\right)^{2}}{400} \times \\
\exp \frac{\left(\ln \left(Q_{10}\right) \times\left(C T_{\text {max }}-T_{\text {opt }}\right)\right)^{2} \times\left(1+\sqrt{1}+\frac{40}{\left(\ln \left(Q_{10}\right) \times\left(C T_{\text {max }}-T_{\text {opt }}+2\right)\right)}\right)^{2}}{400} \times\left(1-\frac{C T_{\text {max }}-T_{b}}{C T_{\text {max }}-T_{\text {opt }}}\right)
\end{gathered}
$$

Where $\mathrm{Q}_{10}$ represents the ratio of the metabolic rate at two temperatures separated by $10^{\circ} \mathrm{C}$ (IUPS Thermal Commission, 2003). Equation 6 of my candidate set was an exponential $x$ power function (Lassiter, 1975):

$$
\dot{\mathrm{V}} \mathrm{O}_{2}=r_{\text {min }} \times \exp ^{a \times\left(T_{b}-T_{o p t}\right)} \times\left(\frac{T_{l}-T_{b}}{T_{l}-T_{o p t}}\right) a \times\left(T_{l}-T_{o p t}\right)
$$




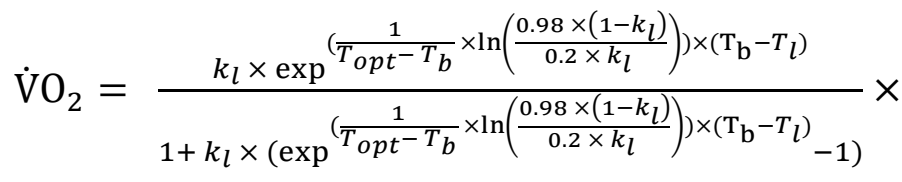

260

$$
\frac{k_{u} \times \exp ^{\left(\frac{1}{T_{o p t^{-T}}} \times \ln \left(\frac{0.98 \times\left(1-k_{u}\right)}{0.2 \times k_{u}}\right)\right) \times\left(\mathrm{T}_{\mathrm{b}}-T_{u}\right)}}{1+k_{u} \times\left(\exp ^{\left(\frac{1}{T_{o p t^{-T}}} \times \ln \left(\frac{0.98 \times\left(1-k_{u}\right)}{0.2 \times k_{u}}\right)\right) \times\left(\mathrm{T}_{\mathrm{b}}-T_{u}\right)}-1\right)}
$$

261

Where $k_{l}$ represents the reaction rate multiplier near the lower critical temperature and $k_{u}$ represents the reaction rate multiplier near the upper critical temperature. Equation 8 was a two-way negative exponential function derived by (Huey \& Stevenson, 1979):

$$
\dot{\mathrm{V}} \mathrm{O}_{2}=r_{\text {max }} \times\left(1-\exp ^{-k_{l} \times\left(T_{b}-T_{l}\right)}\right) \times\left(1-\exp ^{-k_{u} \times\left(T_{b}-T_{u}\right)}\right)
$$

The ninth model in the candidate set was a bi-exponential model, developed independently in two publications (Logan et al., 1976; Tomlinson et al., 2015):

$$
\dot{\mathrm{V}} \mathrm{O}_{2}=r_{\text {min }}+\mathrm{e}^{k_{l} \times \mathrm{T}_{\mathrm{b}}}-\mathrm{e}^{\mathrm{T}_{\mathrm{b}}-T_{d}}
$$

where $T_{d}$ is the temperature of deviation from the pure exponential function.

The tenth model was a six-parameter, exponentially modified logistic function, broadly consistent with those previously published (Hertz, 1983; Crowley, 1985; Kovac et al., 2007):

$$
\dot{\mathrm{V}} \mathrm{O}_{2}=r_{\text {min }}+\frac{r_{\max }-r_{\min }}{1+\mathrm{e}^{k_{l} \times\left(\mathrm{T}_{\mathrm{b}}-T_{i}\right)}}-\left(\mathrm{e}^{k_{u} \times\left(\mathrm{T}_{\mathrm{b}}-T_{d}\right)}\right)
$$

Here, $T_{d}$ is again the temperature of deviation from the pure logistic function. There is also a parameter around which the logistic base function is symmetrical, $T_{i}$.

In recognition of the complexity of this model, containing six parameters, I also tested two simpler models. The first of these simpler models was a modified cubic function (Knies et al., 2006; Knies et al., 2009);

$$
\dot{\mathrm{V}} \mathrm{O}_{2}=r_{\text {min }}+k \times\left(T_{b}{ }^{3}-T_{b}{ }^{2}-T_{b}\right) \times k \times\left(T_{b}-T_{\text {opt }}\right)
$$

Alternatively, a model proposed to describe the thermal performance of plant physiology (Yan \& Hunt, 1999) was used as the fourth candidate model, characterized as:

$$
\dot{\mathrm{V}} \mathrm{O}_{2}=r_{\text {max }} \times\left(\frac{T_{\text {max }}-\mathrm{T}_{\mathrm{b}}}{T_{\max }-T_{o p t}}\right) \times\left(\frac{\mathrm{T}_{\mathrm{b}}}{T_{o p t}}\right)^{\frac{T_{o p t}}{T_{\text {max }}-T_{o p t}}}
$$


Here, $r_{\max }$ indicates the maximal capacity of the organism, or the upper asymptote of the function. $T_{\max }$ indicates the upper thermal tolerance limit, where performance intersects the horizontal axis, (the traditional $\mathrm{CT}_{\max }$ ), and $T_{\text {opt }}$ represents the temperature at which the performance function peaks (the traditional interpretation of $\mathrm{T}_{\mathrm{opt}}$ ). The beta-distribution model formulated by Yan and Hunt (1999) does not provide a parameter analogous to $T_{d}$. As such, I propose that similar thresholds can be estimated from half the breadth between $T_{\text {opt }}$ and $T_{\max }$ thus:

$$
\begin{aligned}
& T_{d(\text { upper })}=T_{o p t}+\left(\frac{T_{\max }-T_{o p t}}{2}\right) \\
& T_{d(\text { lower })}=T_{o p t}-\left(\frac{T_{\text {max }}-T_{o p t}}{2}\right)
\end{aligned}
$$

The four candidate non-linear models were fitted to the combined data for all species, and were compared using an information-criterion approach (Burnham \& Anderson, 2002) using the 'thermperf' package (Bruneaux, 2017) in the $R$ statistical environment version 3.2.1 ( $R$ Core Team, 2016). The most parsimonious model, with the lowest resulting Akaike Information Criterion (AIC), was inferred to capture the maximal complexity of the data with the smallest reduction in likelihood of fit.

Once the best model form was identified in this manner, unique fits were resolved for each species of reptile. Each of these unique fits resulted in a humped relationship, the maximum of which is consistent with a classical interpretation of optimal temperature, Topt (Huey \& Kingsolver, 1989). All nonlinear modelling was undertaken using the ' $n / s 2$ ' package (Grothendieck, 2013) in the $R$ statistical environment version 3.2.1 (R Core Team, 2016). All data are presented as means, as generated from published data.

\section{Results}

Selection of an appropriate thermal performance function

The complete data set extracted from the literature showed the distinctive, humped distribution characteristic of thermal performance data (Figure 2), which eight of the candidate models were capable of mimicking. The functions constructed on the basis of 
enzyme kinetics (Johnson et al., 1954; Ratkowsky et al., 2005) were not able to be fitted to the data describing the metabolic rates of whole animals that I collected here. Of the candidate performance functions, the beta-distribution function (Yan \& Hunt, 1999) best accounted for the variation in the data, followed by the exponentially-penalised logistic function (Kovac et al., 2007), and finally the Arrhenius function (Sharpe \& DeMichele, 1977) (beta-distribution $\mathrm{AICC}=513.7, \mathrm{AIC}$ weight $=0.35, \triangle \mathrm{AIC}=0.00$; exponentially penalized logistic $\mathrm{AICC}=514.1, \mathrm{AIC}$ weight $=0.29, \triangle \mathrm{AIC}=0.35 ;$ Arrhenius $\mathrm{AICC}=515.1, \mathrm{AIC}$ weight $=0.18, \triangle \mathrm{AIC}$ $=1.31$ ). All other candidate models were more than two AIC units distant from the best model (Table 2). The residuals resulting from the beta-distribution function had the narrowest range (-0.89 to $\left.5.51 \mathrm{~mL} \mathrm{O} 2 \cdot \mathrm{g}^{-0.8} \cdot \mathrm{h}^{-1}\right)$, followed by the exponentially penalized logistic (-0.85 to 5.55 $\left.\mathrm{mL} \mathrm{O} 2 \cdot \mathrm{g}^{-0.8} \cdot \mathrm{h}^{-1}\right)$, and finally the Arrhenius function $\left(-0.91\right.$ to $\left.5.53 \mathrm{~mL} \mathrm{O} 2 \cdot \mathrm{g}^{-0.8} \cdot \mathrm{h}^{-1}\right)$. Of the three, however, the beta-distribution function best indicated the decline in metabolic rate that is expected beyond an upper thermal threshold, projected at $48.1{ }^{\circ} \mathrm{C}$, and at $57.0^{\circ} \mathrm{C}$ for the exponentially penalized logistic function. The Arrhenius function did not identify a peak for this data set. The temperature range between the peak of the function and $\mathrm{CT}_{\max }$ was $23.0^{\circ} \mathrm{C}$ for the beta-distribution function, compared to $6.6^{\circ} \mathrm{C}$ for the exponentially-penalized logistic. The Arrhenius function cannot be resolved in such a manner as to estimate $\mathrm{CT}_{\max }$, because the function never intersects the horizontal axis, so mathematically the tolerance breadth of this function is infinite. On these bases I sought ways of parameterizing the thermal optima of the individual reptile species by applying the beta-distribution function, as the best model with the most plausible physiological interpretations.

\section{Parameterizing thermal optima}

The beta-distribution function could be grouped into unique parameters for each family (Figure 3) and for each of the nine study species (Table 3). Each species-specific function facilitated the estimation of an optimum at the peak of the thermal performance function, $T_{\text {opt. }}$ A lower threshold, $T_{d(\text { lower) }}$ could also be estimated for each species from the breadth between the parameterized $T_{\text {opt }}$ and $T_{\max } . T_{\text {opt }}$ ranged between $34.0^{\circ} \mathrm{C}$ and $41.3{ }^{\circ} \mathrm{C}$, while $T_{d(\text { lower) }}$ ranged from $29.7^{\circ} \mathrm{C}$ to $38.5^{\circ} \mathrm{C}$ (Table 1). There was a strong correlation between $T_{\text {pref }}$ and $T_{d}$ across all species $(r=0.72)$ and also between $T_{\text {pref }}$ and $T_{\text {opt }}$ across all species $(r=0.78)$ However, the $T_{d}$ estimates were much closer to equivalence with $T_{\text {pref }}$ than were the $T_{\text {opt }}$ 
estimates (Figure 4). This was supported statistically, where there were no differences between paired $T_{\text {pref }}$ and $T_{d(\text { lower) }}$ estimates $\left(\mathrm{t}_{8}=0.274, \mathrm{p}=0.791\right)$, but $T_{\text {opt }}$ estimates were higher than the observed $T_{\text {pref }}$ of the species $\left(t_{8}=6.77, p=1.40 \times 10^{-4}\right)$. The $T_{\max }$ estimates resulting from beta-distribution functions fitted for each species were also not significantly different to the published $\mathrm{CT}_{\max }$ values $\left(\mathrm{t}_{5}=1.50, \mathrm{p}=0.192\right)$.

\section{Discussion}

The initial aim of this study was to identify the most appropriate of the diverse candidate set of non-linear functions proposed to represent thermal performance by ectotherms. Of these, three functions were statistically indistinguishable in describing the pattern of thermal performance in metabolic rates of reptiles, including the beta-distribution function (Yan \& Hunt, 1999), the exponentially-penalized logistic function (Kovac et al., 2007) and the Arrhenius function (Sharpe \& DeMichele, 1977). However, there are a number of idiosyncrasies associated with adapting the Arrhenius function to model metabolic rates. Firstly, it is dependent upon a reference temperature (the $T_{R}$ parameter) which I fitted on the basis of the data, but which previously appears to have been selected somewhat arbitrarily (Arnall et al., 2014). The lack of a parameterized $r_{\min }$ also assumes that the minimum metabolic rate is zero, which is a relic of its original application to insect development rates (Sharpe \& DeMichele, 1977). This is captured by an implicit step change in rates between $k_{L}$ and $k_{R}$ (Eqn. 3.2), but it does not parameterize an estimate of the standard metabolic rate (SMR), which is the minimum maintenance cost of a living animal. Secondly, the resulting function does not resolve $\mathrm{CT}_{\max }$ in the manner of the other candidate models tested (i.e. it does not ever intersect the temperature axis). Finally, it applies no theoretical upper limit to metabolic rates (or a peak metabolic rate; PMR), assuming that uninhibited reactions will increase in speed, which makes it increasingly complicated to apply to data sets where seasonal acclimation or diverse phylogeny can imply interactions between temperature and PMR. There is an emerging literature discussing the disconnect between statistical viability and biological plausibility (Martinez-Abrain, 2008; Halsey et al., 2015), and I contend that the Arrhenius function, while being statistically indistinguishable from the beta-distribution and exponentially-penalised logistic functions in its ability to characterize ectothermic thermal 
371 performance, its interpretive value is limited because of the five shortcomings in biological

372 relevance described above.

373 A biologically relevant function to describe thermal performance by ectotherms must have some further components beyond the simple concepts that performance declines beyond an upper and lower threshold, but increases within those bounds. The assumptions discussed in the introduction, that 1) there must be both a lower and upper horizon to performance, 2) the increase from minimum to maximum must be continuous and non-linear as a result of the thermal kinetics of chemical reactions (Angilletta, 2009), and 3) there must be an upper tolerance threshold, establish at least four parameters integral to the more physiologically appropriate models, $r_{\min }, r_{\max }, T_{\text {opt }}$, and $T_{d(\text { (lower). }}$. Hence, the most statistically robust and physiologically relevant of the four candidate functions was the beta-distribution model, which was originally developed to describe plant thermal physiology (Yan \& Hunt, 1999). As with the Arrhenius model, this function assumes that $r_{\min }$ is zero, as a relic of its development in the context of growth rates, but it is capable of estimating $r_{\max }$ and two critical thermal tolerance thresholds. As further data are collected, these estimated values may provide a more objective comparative approach to understanding ecological and evolutionary patterns in the energetic requirements of ectotherms. This task remains complicated by the question of the most appropriate temperature at which to make comparative measurements (Huey \& Stevenson, 1979; Atkinson, 1994).

The beta-distribution function provides estimates of two thresholds of thermal tolerance, $T_{\text {opt }}$ representing the classical interpretation of thermal optimum at the peak of the performance function (Huey \& Kingsolver, 1989, 1993), and an upper threshold, $T_{\max }$, which closely approximates $\mathrm{CT}_{\max }$. Using these two parameters in concert, however, it is possible to calculate two further threshold points, the upper and lower $T_{d}$. The lower appears to approximate $T_{\text {pref }}$ in ectothermic reptiles, and I venture that the upper may represent the body temperature at which the animal actively seeks refuge, as is used to parameterize some mechanistic niche envelope models (e.g. Kearney and Porter (2016)). While there are established techniques to identify the performance breadth based upon proportions of maximal performance (usually $80 \%$ or $95 \%$ thresholds) as has often been applied to locomotor performance (e.g. van Berkum (1988); Huey et al. (1989); Navas (1996); Angilletta 
studies. It is notable that the scope between metabolic rates objectively estimated at $T_{d(\text { lower) }}$ and $T_{\text {opt }}$ in all cases is approximately $90 \%$ (Table 1 ), regardless of the phylogenetic heritage or ecological niche and biome in which the species originated (van Berkum, 1988).

\section{Statistical considerations}

Non-linear regression is an approach to studying a number of physiological processes, including dose responses (Ritz et al., 2015), water relations in plants (Lewandrowski et al., 2016), and thermal performance in both endotherms (Tomlinson, 2016) and ectotherms (Hertz, 1983; Crowley, 1985; Kovac et al., 2007; Tomlinson \& Menz, 2015; Tomlinson \& Phillips, 2015). There are a number of packages in the $R$ statistical environment that can automate this process, including the 'drc' package (Ritz \& Streibig, 2012; Ritz et al., 2015). I caution, however, that it is critical to understand both the parameters and structures of the functions used, and their physiological analogues. The beta-distribution function applied here, for example, is only made appropriate if temperature is converted from degrees Celsius to Kelvin, because in this format there are no hard limits in the independent variable (i.e. $T_{a}=$ $0{ }^{\circ} \mathrm{C}$ is just another point along the continuum). If the function is fitted in degrees Celsius it become undefined at temperatures below zero, and clearly loses relevance to the real world. This is easily remedied by the addition of 273 to all temperature components of the function, meaning that all parameters are still fitted in degrees Celsius, thus:

$$
\dot{\mathrm{V}} \mathrm{O}_{2}=W_{f} \times\left(\frac{\left(T_{\max }+273\right)-\left(\mathrm{T}_{\mathrm{a}}+273\right)}{\left(T_{\max }+273\right)-\left(T_{o p t}+273\right)}\right) \times\left(\frac{\left(\mathrm{T}_{\mathrm{a}}+273\right)}{\left(T_{o p t}+273\right)}\right)^{\frac{\left(T_{o p t}+273\right)}{\left(T_{m a x}+273\right)-\left(T_{o p t}+273\right)}}
$$

It is also critically important to understand the structure of the data required to fit these functions. Although a non-linear regression approach is the most appropriate to interrogate thermal biology, it requires a specific experimental design to accommodate the analysis appropriately, and this needs to be considered prior to the collection of data. Experimental design was a substantial constraint on the selection of appropriate data for this study; the thermal performance data for only the nine species selected had been collected over a wide enough temperature range to capture the decline in metabolic rate beyond the upper 
tolerance threshold, despite the fact that there were numerous other species available in the literature where performance had been measured over a narrower range (see Appendices). In the event that further data are to be collected to test these functions, it is critical that measurements are made as far beyond this threshold as is ethically defensible. Furthermore, studies should increase the number of intervals in the key parts of the range to increase the sensitivity of the fitted function to critical turning points, consistent with discussion by Knies and Kingsolver (2010) concerning $\mathrm{T}_{\mathrm{b}}$ near $\mathrm{T}_{\mathrm{opt}}$.

Nonlinear regression using the ' $n / s^{\prime}$ protocol in the $R$ statistical environment assumes a normal distribution of errors (Ritz \& Streibig, 2008; Baty et al., 2015). Studies such as this fall prey to the quality of data that can be extracted from the published literature. Ideally, had I experimentally collected all these data myself I would have access to all the individual stat required to ensure independence of the data, such as specific temperatures, body mass and individual identifications for the purposes of identifying and accounting for deviations from a normal distribution of errors. Failing the ability to incorporate these into a repeated measures design, or as a series of random factors within my analyses, I'm restricted to the next best thing, which is to acknowledge this uncontrolled effect. The sample sizes in my data are not equal, and some of my data will bear a flattening of the variance structure resulting from the application of average body masses into my calculations. Given that these effects should be equivalent across all the models that I applied here, however, I feel that this is at least consistent across my analyses.

Why "suboptimal" is optimal

Several discussions have identified a lack of congruence between the optimal performance temperature ( $\left.T_{\text {opt }}\right)$ at the peak of the performance curve, and the preferred body temperature ( $T_{\text {pref }}$ ) of many reptiles (Martin \& Huey, 2008; Dowd et al., 2015). My question was parameterized thus: if $T_{o p t}$ is not indicative of thermal preferences and thermoregulatory behavior, does an appropriate non-linear function parameterize more accurate ways to estimate them? The preferred body temperatures published for the reptiles studied here were most closely approximated by $T_{d(l o w e r),}$ rather than $T_{\text {opt }}$ (Figure 4), estimated from the beta-distribution function. Where $T_{\text {opt }}$ is the mathematical representation of the thermal 
optimum at the peak of the performance function, t-testing indicated that the fitted $T_{o p t}$ values were higher than the published $T_{\text {pref. }}$. The lower temperature threshold that I calculated at $T_{d(l o w e r)}$ was statistically indistinguishable from $T_{\text {pref }}$ of the nine species studied.

One theory underpinning the apparent paradox that mathematically suboptimal temperatures are in fact biologically optimal rests on the asymmetry of thermal performance curves, where performance (or apparent fitness) declines much more rapidly when $T_{b}$ exceeds $T_{\text {opt }}$ than when $T_{b}$ is below $T_{o p t}$ (Huey \& Stevenson, 1979; Gilchrist, 1995; Izem \& Kingsolver, 2005; Martin \& Huey, 2008). In this context, as well as avoiding the risk of rapid declines in fitness when $T_{b}$ exceeds $T_{o p t}$, fitness should also be optimized across the thermal performance function. This results in a relationship between the distance between Tpref and Topt and the degree of asymmetry of the thermal performance function (Martin \& Huey, 2008). When the thermal performance functions that I resolved here for each species were assessed for asymmetry in this manner, however, the relationship appeared to be the reverse of that expected. Although performance optima are typically characterized using only a single performance metric, such as locomotor capacity, fecundity, or metabolic rate, there is an implicit assumption that they are all proxy indicators for the thermal effects on enzymecatalyzed reactions (Sharpe \& DeMichele, 1977; Huey \& Kingsolver, 1989). Regardless of whether that assumption is justified, there should be strong selection to maximize lifetime fitness by centering $T_{\text {pref }}$ below the $T_{\text {opt }}$ (Martin \& Huey, 2008), because performance declines so rapidly beyond this tolerance threshold regardless of underlying mechanisms. As such, I remain unconvinced that the small number of species that I have investigated here suitably replicate the data set reported by Martin \& Huey (2008) for sprint speed to provide much support in comparing the patterns of performance asymmetry and thermal preference breadth between the two.

Alternative to Martin and Huey (2008), the oxygen- and capacity-limited thermal tolerance (OCLTT) theory (eg. Pörtner (2010)) suggests that maintaining a buffer of aerobic scope could be the mechanistic basis to the observed patterns, whereby ectotherms maintain $T_{\text {pref }}$ below the putative performance maximum. The theory poses that critical temperature thresholds represent the transition points from aerobic to anaerobic mitochondrial metabolism (Pörtner, 2010). Furthermore, Pörtner (2010) concludes that oxygen limitation sets in prior to 
functional failure. Bearing in mind that aerobic scope best represented as the maximum amount of oxygen available for any aerobic activity above routine for any specific temperature, maintaining $T_{b}$ at a point lower than $T_{o p t}$ should allow the organism to maintain some scope for increased metabolic output prior to catastrophic oxygen limitation. Essentially, one way of interpreting these theories is in terms of an "engineering failsafe": maintaining $T_{b}$ at levels below the temperature where the performance curve peaks allows some leeway for metabolic rates to increase in response to environmental stimuli or increased exertion. Assuming that the metabolic rates of the fitted performance functions for each species genuinely reflect the maximum aerobic capacity of the reptiles studied, maintaining body temperatures close to the estimated $T_{d}$ values should allow the reptiles in question to consistently maintain an aerobic scope of about $10 \%$ of their maximal capacity (Table 1).This is advantageous compared to maintaining a higher $T_{b}$ close to $T_{o p t}$ because, consistent with Pörtner (2010), maintaining $T_{b}$ at levels that appear suboptimal allows the animals to remain responsive to their environment, with some capacity for increased $\mathrm{O}_{2}$ consumption required for increased activity associated with foraging, escaping predation and other behaviors.

The species included in this analysis represent a broad spectrum of ecological niches and phylogenetic spread. Both of these elements undoubtedly contributed some variation to my findings, some of which can be speculated at but some remain too data-deficient to interpret, and I have therefore chosen not to speculate upon them. Generally, a study with the phylogenetic breadth represented here should include phylogenetic corrections (Feder, 1987; Garland \& Adolph, 1994). The data requirement that the temperatures over which performance was measured were broad enough to indicate a decline in metabolic rate constrained my sample size, limiting scope for accommodating phylogenetic corrections.

Furthermore, there is a disconnect between the physiological heritage of the term "optimal temperature" which was initially coined in a mathematical context as the point where performance was maximal, and evolutionary contexts where it implies lifetime fitness gains (Martin \& Huey, 2008). Obviously lifetime fitness is the culmination of a wide array of traits and pressures, not all of which will have the same thermal requirements, and some of which may trade off against each other. The final caveat on the generality of the beta-distribution model's ecological and evolutionary interpretations is that although this function appears 
competent to describe the thermal performance of metabolic rate for the reptiles described here, it may not apply to all ectotherms (Dowd et al., 2015) or all life history stages (Kingsolver et al., 2011), nor to all possible performance traits (Huey, 1982). The ecological and evolutionary interpretations of this modelling approach, therefore, remain tentative until further data can contribute to these models. Nevertheless, having a broadly applicable model of thermal performance should facilitate these kinds of comparisons, and should be rigorously tested.

\section{Conclusions}

Thermal performance by ectotherms is a non-linear interaction between physiological processes (including the regulated body temperature) and ambient temperature. Although any performance metric should conform to the same relationship, the metabolic rates of ectotherms are best related to $T_{a}$ by a beta-distribution function. This function provides the capacity to calculate the parameter $T_{d}$, which approximates the preferred body temperatures of the animal, at least in the nine species of reptiles that I investigated here. This threshold, while not consistent with a classical paradigm of thermal optimality in ectotherms, is consistent with existing alternative hypotheses.

\section{Acknowledgements}

Financial support for S. Tomlinson was provided by Australian Research Council grant IC150100041. The author gratefully acknowledges S. Arnall (formerly University of Western Australia), W. Lewandrowski (Department of Biodiversity, Conservation and Attractions Western Australia), M. Kearney (University of Melbourne), and P. Withers (University of Western Australia) for informative discussions on the nature of thermal performance functions and ectothermic metabolic rates. L. Gilson (Curtin University) provided invaluable advice on flow and clarity of the draft. I also acknowledge the suggestions and input of several anonymous peer reviewers, without whose commentary this manuscript would not have evolved to the level of completion that is has. 
Andrews, R.M. \& Pough, F.H. (1985) Metabolism of squamate reptiles: allometric and ecological relationships. Physiological Zoology, 58, 214-231.

Angilletta, M.J. (2006) Estimating and comparing thermal performance curves. Journal of Thermal Biology, 31, 541-545.

Angilletta, M.J., Niewiarowski, P.H. \& Navas, C.A. (2002) The evolution of thermal physiology in ectotherms. Journal of Thermal Biology, 27, 249-268.

Angilletta, M.J., Wilson, R.S., Navas, C.A. \& James, R.S. (2003) Tradeoffs and the evolution of thermal reaction norms. Trends in Ecology and Evolution, 18, 234-240.

Angilletta, M.J.J. (2009) Thermal Adaptation: a Theoretical and Empirical Synthesis. Oxford University Press, Oxford.

Arnall, S.G., Kuchling, G. \& Mitchell, N.J. (2014) A thermal profile of metabolic performance in the rare Australian chelid,Pseudemydura umbrina. Australian Journal of Zoology, 62, 448-453.

Atkinson, D. (1994) Temperature and organism size - a biological law for ectotherms? Adv. Ecol. Res., 25, 1-58.

Bartholomew, G.A. (1966) A field study of temperature relations in the Galapagos marine iguana. Copeia, 1966, 241-250.

Baty, F., Ritz, C., Charles, S., Brutsche, M., Flandrois, J.-P. \& Delignette-Muller, M.-L. (2015) A toolbox for nonlinear regression in R: The package nlstools. Journal of Statistical Software, 66, 1-21.

Bennett, A.F. (1972) The effect of activity on oxygen consumption, oxygen debt, and heart rate in the lizards Varanus gouldii and Sauromalus hispidus. Journal of Comparative Physiology A, 79, 259280.

Bennett, A.F. \& Dawson, W.R. (1972) Aerobic and anaerobic metabolism during activity in the lizard Dipsosaurus dorsalis. Journal of Comparative Physiology A, 81, 289-299.

Bennett, A.F. \& John-Alder, H. (1986) Thermal relations of some Australian skinks (Sauria: Scincidae). Copeia, 1986, 57-64.

Bennett, A.F., Dawson, W.R. \& Bartholomew, G.A. (1975) Effects of activity and temperature on aerobic and anaerobic metabolism in the Galapagos marine iguana. Journal of Comparative Physiology B, 100, 317-329.

Bruneaux, M. (2017) thermPerf: model fitting for thermal performance curves. R package version 0.0.1. Brusch, G.A., Taylor, E.N. \& Whitfield, S.M. (2016) Turn up the heat: thermal tolerances of lizards at La Selva, Costa Rica. Oecologia, 180, 325-334.

Buckley, L. (2008) Linking traits to energetics and population dynamics to predict lizard ranges in changing environments. American Naturalist, 171, E1-E19.

Burnham, K.P. \& Anderson, D.R. (2002) Model Selection and Multimodel Inference: a Practical Information-theoretic Approach, $2^{\text {nd }}$ Edition. Springer, New York.

Chown, S.L., Marais, E., Terblanche, J.S., Klok, C.J., Lighton, J.R.B. \& Blackburn, T.M. (2007) Scaling of insect metabolic rate is inconsistent with the nutrient supply network model. Functional Ecology, 21, 282-290.

Crowley, S.R. (1985) Thermal sensitivity of sprint-running in the lizard Sceloporus undulatus: support for a conservative view of thermal physiology. Oecologia, 66, 219-225.

DeWitt, C.B. (1967) Precision of thermoregulation and its relation to environmental factors in the desert iguana, Dipsosaurus dorsalis. Physiological Zoology, 40, 49-66.

Dowd, W.W., King, F.A. \& Denny, M.W. (2015) Thermal variation, thermal extremes and the physiological performance of individuals. Journal of Experimental Biology, 218, 1956-1967.

Evans, T.G., Diamond, S.E. \& Kelly, M.W. (2015) Mechanistic species distribution modelling as a link between physiology and conservation. Conservation Physiology, 3, cov56.

Feder, M.E. (1987) The analysis of physiological diversity: the prospects for pattern documentation and general questions in ecological physiology. New Directions in Ecological Physiology. (ed. by M.E. Feder, A.F. Bennett, W.G. Burggren and R.B. Huey), pp. 38-75. Cambridge University Press, Cambridge. 
Frederich, M. \& Pörtner, H.O. (2000) Oxygen limitation of thermal tolerance defined by cardiac and ventilatory performance in the spider crab, Maja squinado. American Journal of Physiology, 279, R1531-R1538.

Garland, T.J. \& Adolph, S.C. (1994) Why not to do two-species comparative studies: Limitations on inferring adaptation. Physiological Zoology, 67, 797-828.

Gatten, R.E. (1974) Effects of temperature and activity on aerobic and anaerobic metabolism and heart rate in the turtles Pseudemys scripta and Terrapene ornata. Comparative Biochemistry and Physiology A, 48, 619-648.

Gilchrist, G.W. (1995) Specialists and generalists in changing environments I: Fitness landscapes of thermal sensitivity. American Naturalist, 146, 252-270.

Gillooly, J.F., Brown, J.H., West, G.B., Savage, V.M. \& Charnov, E.L. (2001) Effects of Size and Temperature on Metabolic Rate. Science, 293, 2248-2251.

Gillooly, J.F., Charnov, E.L., West, G.B., Savage, V.M. \& Brown, J.H. (2002) Effects of size and temperature on developmental time. Nature, 40, 70-73.

Grothendieck, G. (2013) NIs2: Non-linear regression with brute force. CRAN R-project.

Gurka, M.J. \& Edwards, L.J. (2011) Estimating variance components and random effects using the BoxCox transformation in the linear mixed model. Communications in Statistics - Theory and Methods, 40, 515-531.

Halsey, L.G., Curran-Everett, D., Vowler, S.L. \& Drummond, G.B. (2015) The fickle P value generates irreproducible results. Nature Methods, 12, 179-185.

Hayes, J.P. \& Shonkwiler, J.S. (2006) Allometry, antilog transformations, and the perils of prediction on the original scale. Physiological and Biochemical Zoology, 79, 665-674.

Hertz, P.E. (1983) Eurythermy and niche breadth in West Indian Anolis lizards: a reappraisal. Advances in Herpetology and Evolutionary Biology: Essays in honor of Ernest E. Williams (ed. by A.G.J. Rhodin and K. Miyata). Harvard University Museum of Comparative Zoology, Cambridge, Massachusetts.

Hertz, P.E., Huey, R.B. \& Nevo, E. (1983) Homage to Santa Anita: thermal sensitivity of sprint speed in agamid lizards. Evolution, 37, 1075-1084.

Huey, R.B. (1982) Temperature, physiology, and the ecology of reptiles. Biology of the Reptilia, 12, 2591.

Huey, R.B. \& Stevenson, R.D. (1979) Integrating thermal physiology and ecology of ectotherms: A discussion of approaches. American Zoologist, 19, 357-366.

Huey, R.B. \& Kingsolver, J.G. (1989) Evolution of thermal sensitivity of ectotherm performance. Trends in Ecology and Evolution, 4, 131-135.

Huey, R.B. \& Kingsolver, J.G. (1993) Evolution of resistance to high temperature in ectotherms. American Naturalist, 142, S21-S46.

Huey, R.B., Niewiarowski, P.H., Kaufmann, J. \& Herron, J.C. (1989) Thermal biology of nocturnal ectotherms: is sprint performance of geckos maximal at low body temperatures? Physiological Zoology, 62, 488-504.

IUPS Thermal Commission (2003) Glossary of terms for thermal physiology. Journal of Thermal Biology, 28, 75-106.

Izem, R. \& Kingsolver, J.G. (2005) Variation in continuous reaction norms: quantifying directions of biological interest. American Naturalist, 166, 277-289.

Johnson, F.H., Eyring, H. \& Polissar, M.J. (1954) The Kinetic Basis of Molecular Biology. John Wiley And Sons, New York.

Kearney, M., Porter, W., Williams, C., Ritchie, S. \& Hoffmann, A.A. (2009) Integrating biophysical models and evolutionary theory to predict climatic impacts on species' ranges: the dengue mosquito Aedes aegypti in Australia. Functional Ecology, 23, 528-538.

Kearney, M.R. \& Porter, W.P. (2016) NicheMapR-an R package for biophysical modelling: the microclimate model. Ecography, doi: [10.1111/ecog.02360] 
Kingsolver, J.G., Woods, H.A., Buckley, L.B., Potter, K.A., MacLean, H.J. \& Higgins, J.K. (2011) Complex life cycles and the responses of insects to climate change. Integrative and Comparative Biology, 51, 719-732.

Knies, J.L. \& Kingsolver, J.G. (2010) Erroneous Arrhenius: modified Arrhenius model best explains the temperature dependence of ectotherm fitness. The American Naturalist, 176, 227-233.

Knies, J.L., Kingsolver, J.G. \& Burch, C.L. (2009) Hotter is better and broader: thermal sensitivity of fitness in a population of bacteriophages. The American Naturalist, 173, 419-430.

Knies, J.L., Izem, R., Supler, K.L., Kingsolver, J.G. \& Burch, C.L. (2006) The genetic basis of thermal reaction norm evolution in lab and natural phage populations. PloS Biology, 4, e201.

Kooijman, S.A.L.M. (2010) Dynamic Energy Budget Theory for Metabolic Organisation, 3rd Edition. Cambridge University Press, Cambridge.

Kovac, H., Stabentheiner, A., Hetz, S.K., Petz, M. \& Crailsheim, K. (2007) Respiration of resting honeybees. Journal of Insect Physiology, 53, 1250-1261.

Lassiter, R.R. ( 1975) Modeling dynamics of biological and chemical components of aquatic ecosystems. . National Environmental Research Center, U.S. Environmental Protection Agency, Corvallis, Oregon.

Lehman, J.T., Botkin, D.B. \& Likens, G.E. (1975) The assumptions and rationales of a computer model of phytoplankton population dynamics. Limnology and Oceanography, 20, 343-364.

Lewandrowski, W., Erickson, T.E., Dixon, K.W. \& Stevens, J.C. (2016) Increasing the germination envelope under water stress improves seedling emergence in two dominant grass species across different pulse rainfall events. Journal of Applied Ecology, doi: 10.1111/13652664.12816

Licht, P. (1964) A comparative study of the thermal dependence of contractility in saurian skeletal muscle. Comparative Biochemistry and Physiology, 13, 27-34.

Licht, P. (1965) Effects of temperature on heart rates of lizards during rest and activity. Physiological Zoology, 38, 129-137.

Lighton, J.R.B. \& Fielden, L.J. (1995) Mass scaling of standard metabolism in ticks: A valid case of low metabolic rates in sit-and-wait strategists. Physiological Zoology, 68, 43-62.

Logan, J.A., Wollkind, D.T., Hoyt, J.C. \& Tanigoshi, L.K. (1976) An analytic model for description of temperature dependent rate phenomena in arthropods. Environmental Entomology, 5, 11301140.

Martin, T.L. \& Huey, R.B. (2008) Why "suboptimal" is optimal: Jensen's inequality and ectotherm thermal preferences. The American Naturalist, 171, E102-E118.

Martinez-Abrain, A. (2008) Statistical significance and biological relevance: A call for a more cautious interpretation of results in ecology. Acta Oecologica, 34, 9-11.

Mason, L.D., Tomlinson, S., Withers, P.C. \& Main, B.Y. (2013) Thermal and hygric physiology of Australian burrowing mygalomorph spiders (Aganippe spp.). journal of comparative Physiology $B, 183,71-82$.

Moberly, W.R. (1968) The metabolic responses of the common iguana, Iguana iguana, to activity under restraint. Comparative Biochemistry and Physiology, 27, 1-20.

Navas, C.A. (1996) Metabolic physiology, locomotor performance, and thermal niche breadth in neotropical anurans. Physiological Zoology, 69, 1481-1501.

O'Neill, R.V., Goldstein, R.A., Shugart, H.H. \& Mankin, J.B. (1972) Terrestrial ecosystem energy model. Eastern Deciduous Forest Biome Memo Report, 72, 19.

Pörtner, H.O. (2001) Climate change and temperature-dependent biogeography: oxygen limitation of thermal tolerance in animals. Naturwissenschaften, 88, 137 - 146.

Pörtner, H.O. (2010) Oxygen- and capacity-limitation of thermal tolerance: a matrix for integrating climate-related stressor effects in marine ecosystems. Journal of Experimental Biology, 213, 881-893. 
Pörtner, H.O., Bennett, A.F., Bozinovic, F., Clarke, A., Lardies, M.A., Lucassen, M., Pelster, B., Schiemer, F. \& Stillman, J.H. (2006) Trade-offs in thermal adaptation: the need for a molecular to ecological integration. Physiological and Biochemical Zoology, 79, 295-313.

$\mathrm{R}$ Core Team (2016) R: A language and environment for statistical computing. R Foundation for Statistical Computing.

Raftery, A.E. (1995) Bayesian model selection in social research. Sociological Methodology, 25, 111163.

Ratkowsky, D.A., Olley, J. \& Ross, T. (2005) Unifying temperature effects on the growth rate of bacteria and the stability of globular proteins. Journal of Theoretical Biology, 233, 351-362.

Ritz, C. \& Streibig, J.C. (2008) Nonlinear Regression with R. Springer, New York.

Ritz, C. \& Streibig, J.C. (2012) Dose response curves and other nonlinear curves in Weed Science and Ecotoxicology with the add-on package drc in R.

Ritz, C., Baty, F., Streibig, J.C. \& Gerhard, D. (2015) Dose-Response Analysis Using R. PLoS ONE, 10, e0146021. doi:10.1371/journal.pone.0146021.

Schäuble, C.S. \& Grigg, G.C. (1998) Thermal ecology of the Australian agamid Pogona barbata. Oecologia, 114, 461-470.

Scholander, P.F., Flagg, W., Walters, W. \& Irving, L. (1953) Climatic adaptation in arctic and tropical poikilotherms. Physiological Zoology, 26, 67-92.

Schoolfield, R.M., Sharpe, P.J.H. \& Magnuson, C.E. (1981) Non-linear regression of biological temperature-dependent rate models based on absolute reaction-rate theory. Journal of Theoretical Biology, 88, 719-731.

Sharpe, P.J. \& DeMichele, D.W. (1977) Reaction kinetics of poikilotherm development. Journal of Theoretical Biology, 64, 649-670.

Snyder, G.K. \& Weathers, W.W. (1976) Physiological responses to temperature in the tropical lizard, Hemidactylus frenatus (Sauria: Gekkonidae). Herpetologica, 32, 252-256.

Somero, G.N. (2002) Thermal physiology and vertical zonation of intertidal animals: Optima, limits, and costs of living. Integrative and Comparative Biology, 42, 780-789.

Somero, G.N. (2005) Linking biogeography to physiology: Evolutionary and acclimatory adjustments of thermal limits. Frontiers in Zoology, 2, 1.

Sommer, A., Klein, B. \& Pörtner, H.O. (1997) Temperature induced anaerobiosis in two populations of the polychaete worm Arenicola marina (L.). Journal of Comparative Physiology, 167B, 25-35.

Spellerberg, I.F. (1972) Temperature tolerances of southeast Australian reptiles examined in relation to reptile thermoregulatory behaviour and distribution. Oecologia, 9, 23-46.

Suarez, R.K. (1996) Upper limits to mass-specific metabolic rates. Annual Review of Physiology, 58, 583-605.

Thornton, K.W. \& Lessem, A.S. (1978) A temperature algorithm for modifying biological rates. Transactions of the American Fisheries Society, 107, 284-287.

Tomlinson, S. (2016) Novel approaches to the calculation and comparison of thermoregulatory parameters: Non-linear regression of metabolic rate and evaporative water loss in Australian rodents. Journal of Thermal Biology, 57, 54-65.

Tomlinson, S. \& Phillips, R.D. (2012) Metabolic rate, evaporative water loss and field activity in response to temperature in an ichneumonid wasp. Journal of Zoology, 287, 81-90.

Tomlinson, S. \& Menz, M.H.M. (2015) Does metabolic rate and evaporative water loss reflect differences in migratory strategy in sexually dimorphic hoverflies? Comparative Biochemistry and Physiology, 190, 61-67.

Tomlinson, S. \& Phillips, R.D. (2015) Differences in metabolic rate and evaporative water loss associated with sexual dimorphism in thynnine wasps. Journal of Insect Physiology, 78, 62-68.

Tomlinson, S., Dixon, K.W., Didham, R.K. \& Bradshaw, S.D. (2015) Physiological plasticity of metabolic rates in the invasive honey bee and an endemic Australian bee species. Journal of Comparative Physiology B, 8, 835-844. 
Tomlinson, S., Webber, B.L., Bradshaw, S.D., Dixon, K.W. \& Renton, M. (2017) Incorporating biophysical ecology into high-resolution restoration targets: insect pollinator habitat suitability models. Restoration Ecology, 26, 338-347.

Tuff, K.T., Tuff, T. \& Davies, K.F. (2016) A framework for integrating thermal biology into fragmentation research. Ecology Letters, DOI: 10.1111/ele.12579

van Berkum, F.H. (1988) Latitudinal patterns of the thermal sensitivity of sprint speed in lizards. The American Naturalist, 132, 327-343.

van Dijk, P.L., Tesch, C., Hardewig, I. \& Portner, H.O. (1999) Physiological disturbances at critically high temperatures: a comparison between stenothermal antarctic and eurythermal temperate eelpouts (Zoarcidae). Journal of Experimental Biology, 202, 3611-3621.

Warburg, M.R. (1965) The influence of ambient temperature and humidity on the body temperature and water loss from two Australian lizards, Tiliqua rugosa Gray (Scincidae) and Amphibolurus barbatus Cuvier (Agamidae). Australian Journal of Zoology, 13, 331-350.

White, F.N. (1973) Temperature and the Galapagos marine iguana - Insights into reptilian thermoregulation. Comparative Biochemistry and Physiology, 45, 503-513.

Wilhoft, D.C. (1958) Observations on preferred body temperature and feeding habits of some selected tropical iguanas. Herpetologica, 14, 161-164.

Wilson, K.J. (1974) The relationship of oxygen supply for activity to body temperature in four species of lizards. Copeia, 1974, 920-934.

Withers, P.C. (1992) Comparative Animal Physiology. Saunders College Publishing, Fort Worth.

Wollkind, D.J., Logan, J.A. \& Berryman, A.A. (1978) Asymptotic methods for modeling biological processes. Researches on Population Ecology, 20, 79-90.

Yan, W. \& Hunt, L.A. (1999) An equation for modelling the temperature response of plants using only the cardinal temperatures. Annals of Botany, 84, 607-614. 
a)

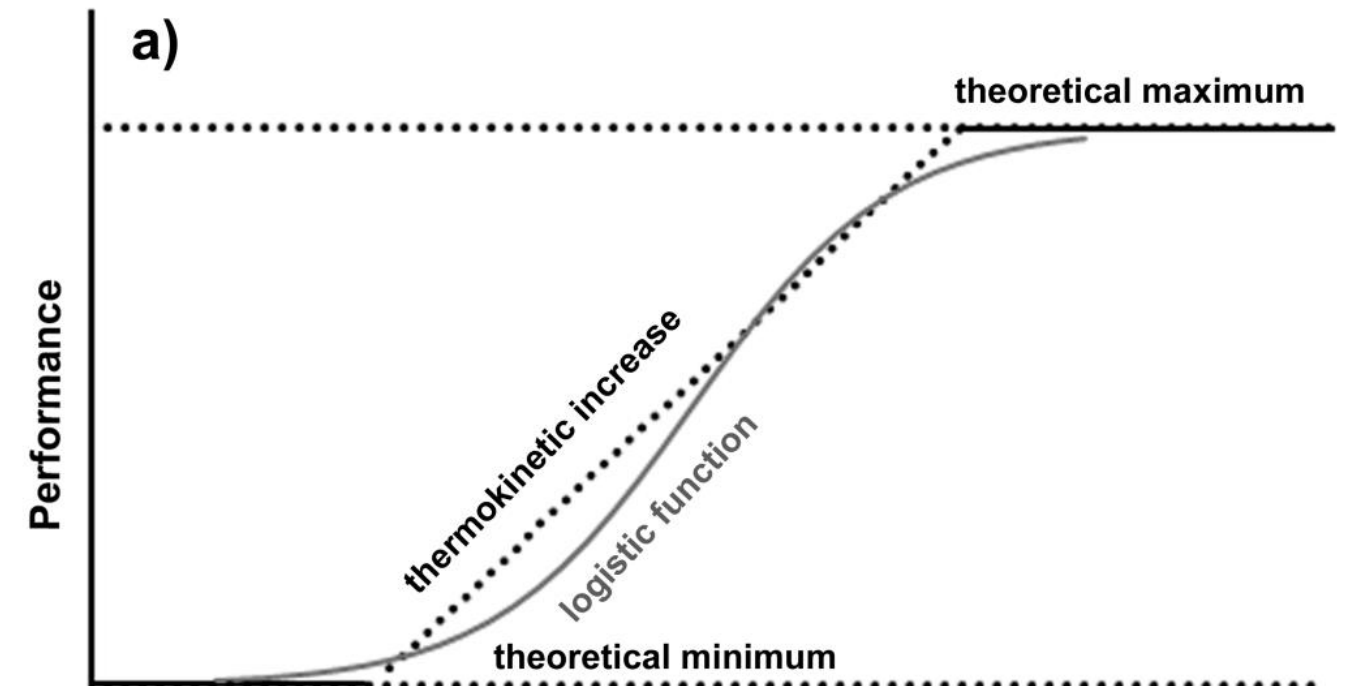

b) enzyme activity

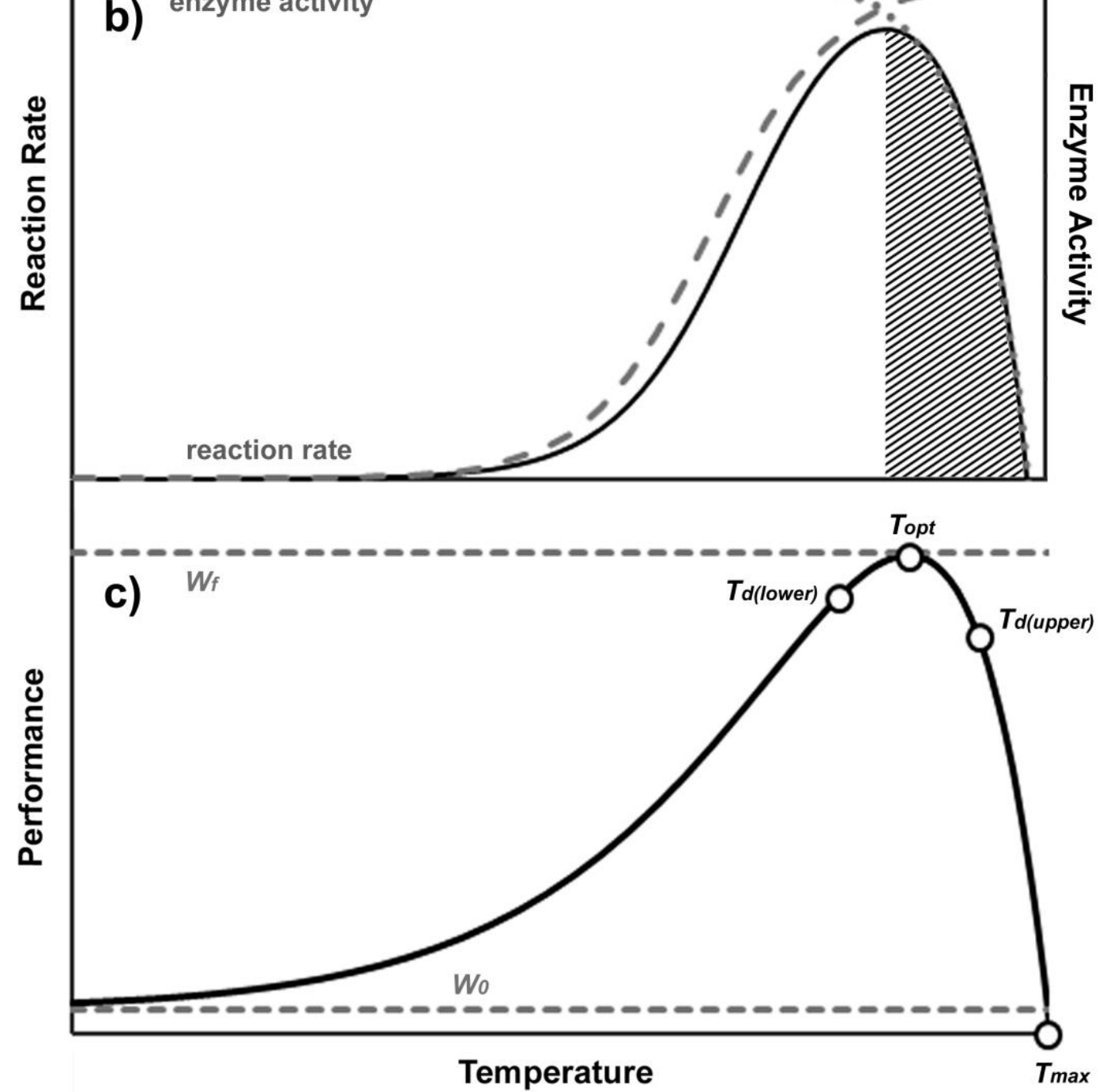


Figure 1: a) A schematic representation on the elements of thermal performance in ectotherms, within the bounds of the thermal tolerance limits. There must be a theoretical minimum to performance, and it must also increase with increasing temperature due to increased thermal kinetics of reaction rates. There should also be a theoretical upper limit to performance imposed by structural limitations. While these could be approached as a piece-wise series of linear fits, a more accurate representation is made by a non-linear approach such as the logistic function shown b) When converted to a non-linear paradigm, increased performance mimics the " $s$ " curve of increasing reaction rates with increasing temperature (dashed grey line). The addition of thermal inhibition of performance implies that, while reaction rates increase, some aspect of physiological constraint is imposed (cross-hatched area), here indicated by enzyme denaturation (dotted line). The interaction between reaction kinetics and physiological constraint results in the characteristic unimodal, asymmetrical performance curve. c) The proposed thermal performance functions examined here are all characterized by some or all parameters that relate to physiological traits. These include a lower limit, $r_{\min }$, and an upper performance asymptote $r_{\max }$. Critical to the question that I explore here, three temperature thresholds can be resolved using these functions: $T_{\max }$ occurs at the only temperature where the function is equal to zero, $T_{\text {opt }}$ occurs at the peak of the function and two $T_{d}$ thresholds can be developed in unique ways from each function. 


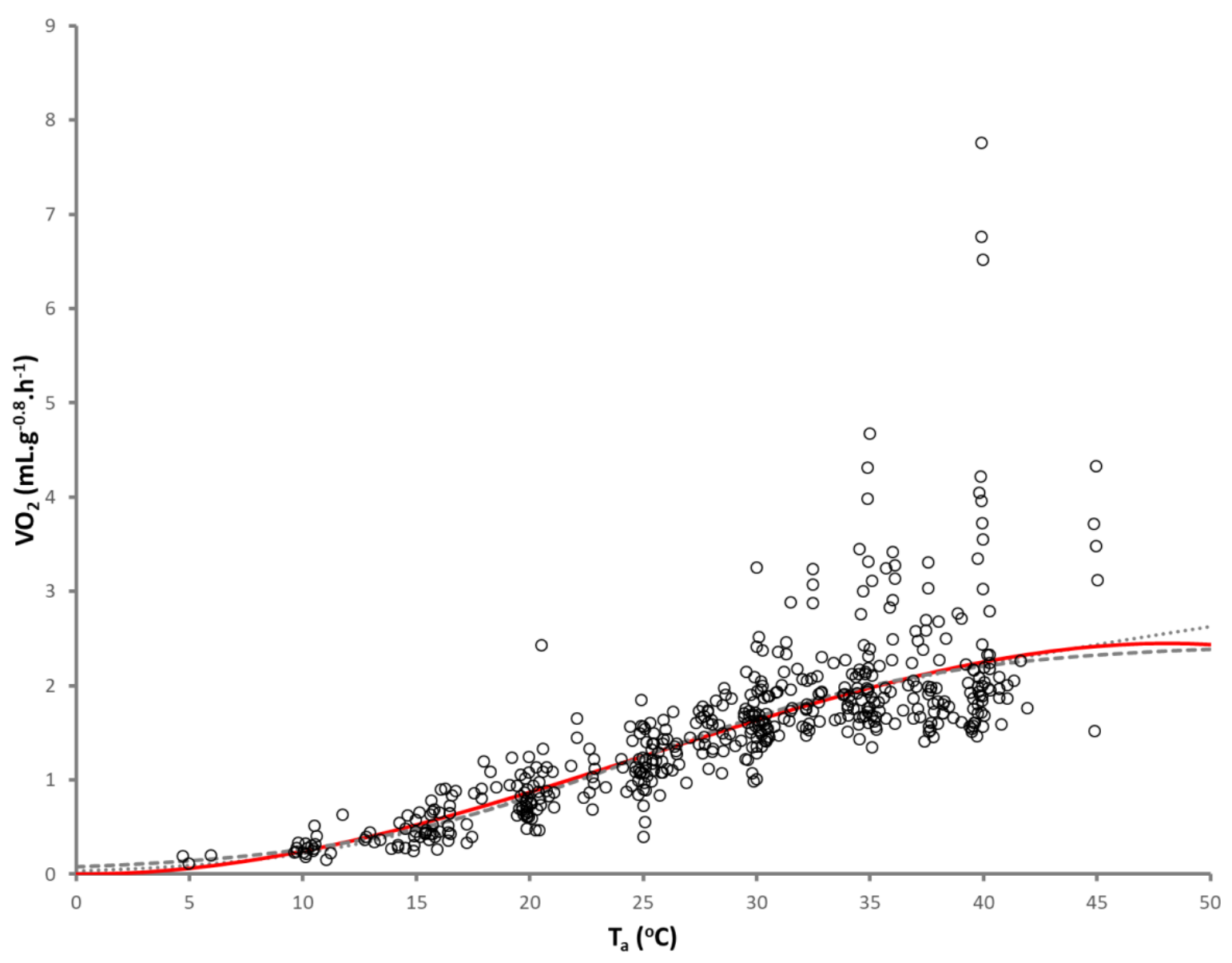

Figure 2: Fitted estimates of the four candidate functions, the Arrhenius curve (grey dotted line), the 796 exponentially penalized logistic curve (grey dashed line), and the beta-distribution curve (red solid 797 line), describing the thermal performance of exercise induced peak metabolic rates in reptiles. The 798 beta-distribution function resulted in the most parsimonious fit (AICC $=513.8$ ), however the 799 exponentially penalized logistic ( $A I C C=514.1$ ), and the Arrhenius function $(A I C C=515.1$ ) were 800 statistical indistinguishable from it, with a $\triangle A I C c$ less than 2.0 (Raftery, 1995). All the other functions 801 tested feel beyond this limit. 


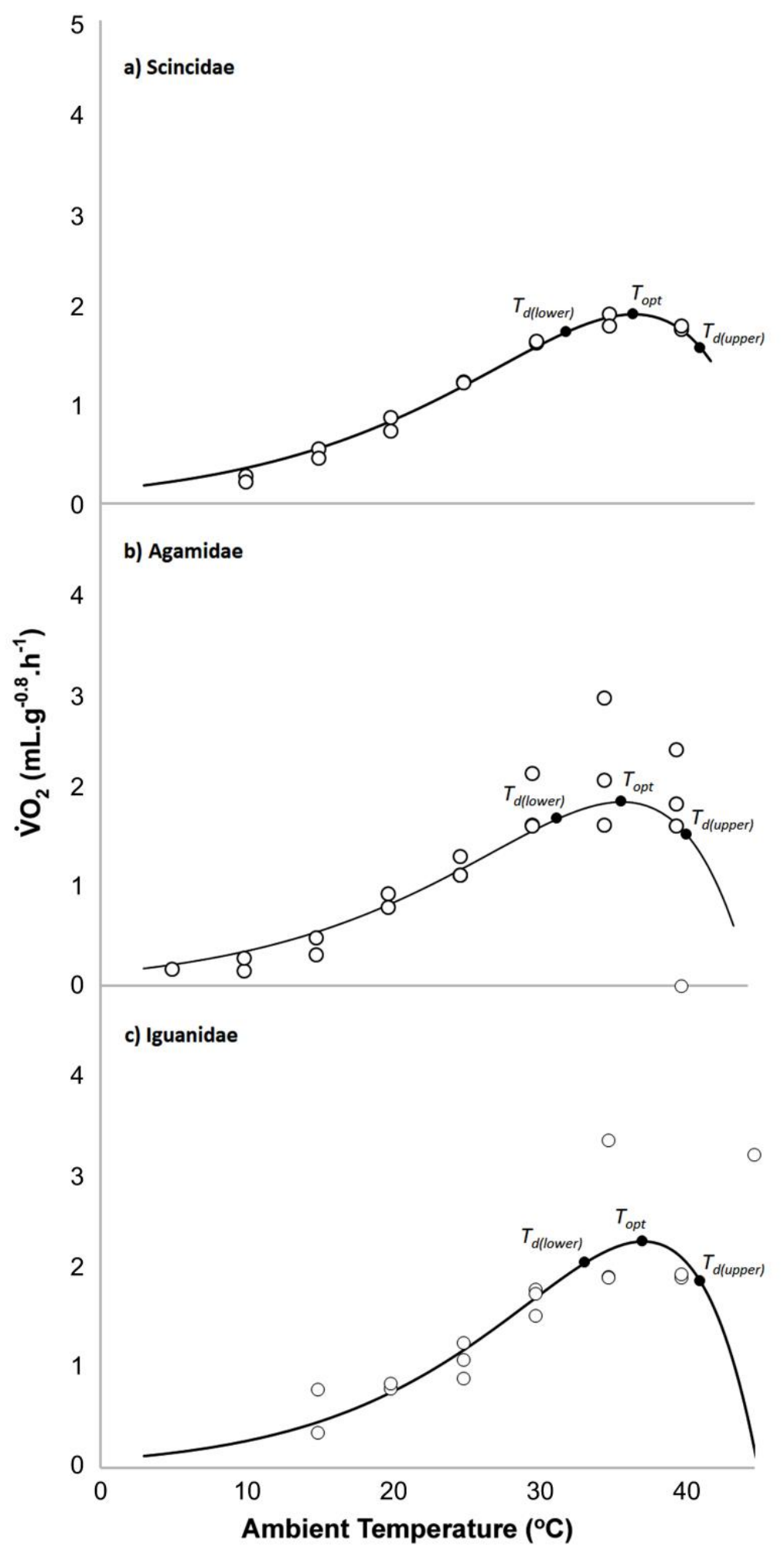

Figure 3: Beta-distribution performance functions of allometrically corrected maximum metabolic rates for the nine reptile species examined here from a) the Scincidae, b) the Agamidae and c) the Iguanidae. The solid, black line represents the average beta-distribution function for each family. $T_{\max }$ is parameterized by the function directly, while $T_{d}$ is parameterized by the first derivative of the function. The points are the average published metabolic rates measured for each species at each temperature. 


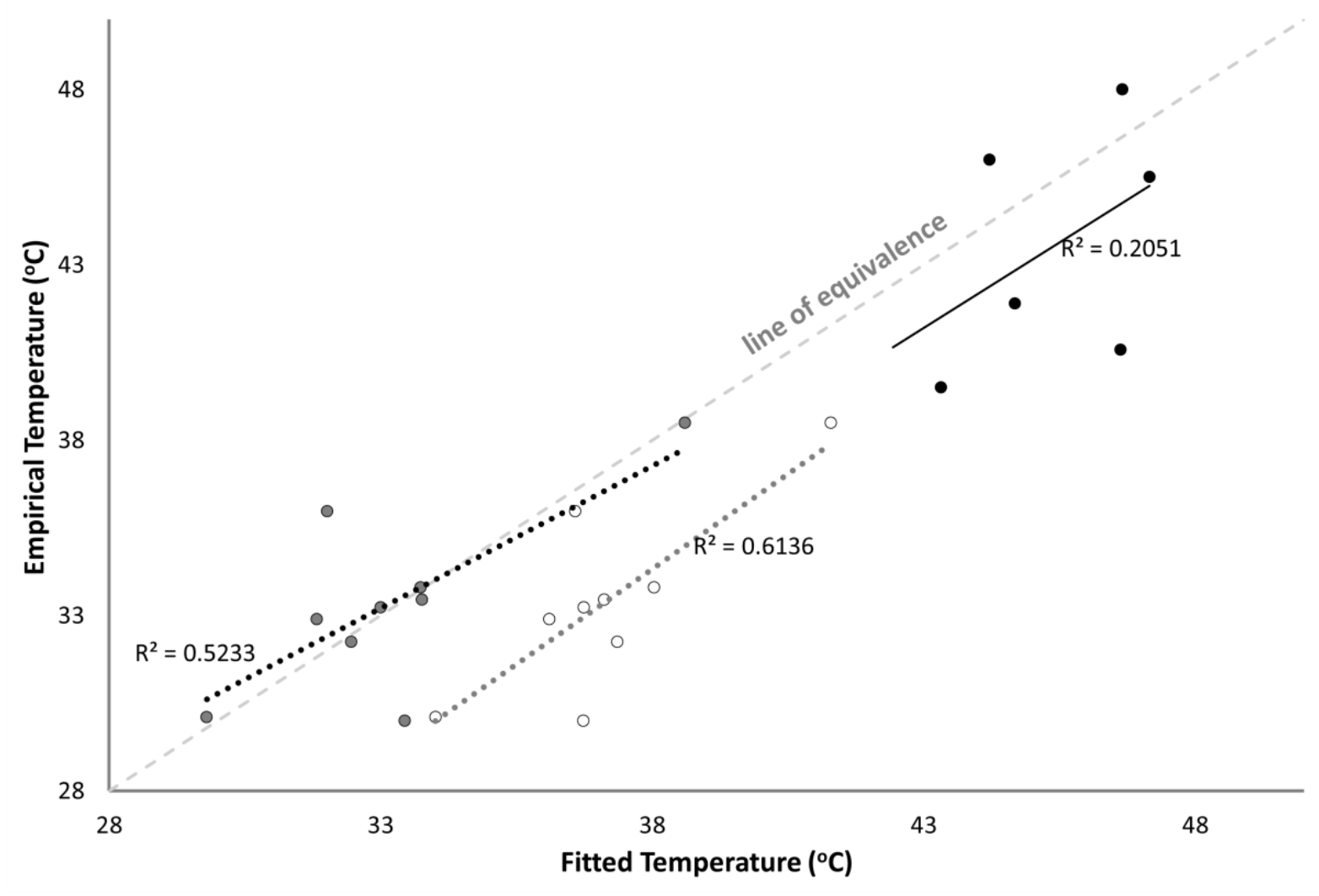

810 Figure 4: Relationships between $T_{\text {opt }}(0)$ and $T_{d(l \text { lower })}(\bullet)$ values interpolated from the species-specific

811 beta-distribution fits and published $T_{\text {pref }}$ for each species, and between $T_{\max }(\bullet)$ parameters resulting 812 from the beta-distribution fits and published $\mathrm{CT}_{\max }$ for each species. The lines represent simple 813 correlations to indicate trends, however they serve to show that $T_{d(l o w e r)}$ predictions fall much more 814 closely upon the line of equivalence than $T_{\text {opt }}$ predictions resulting from the beta-distribution function, 815 while the $T_{\max }$ parameter is relatively consistent with published $\mathrm{CT}_{\max }$ values. 
Table 1: Mass and thermal characteristics of the nine species of reptile used to investigate the thermal performance of metabolic rates. Mass, $T_{\text {pref }}$ and $817 \mathrm{CT}_{\max }$ values were extracted from published literature sources, while $T_{\text {opt }}$ and $T_{d}$ were interpolated from fitted exponentially penalized logistic thermal 818 performance functions. The number of data points contributing to each species is indicated in the column headed $\mathrm{n}$. Breadth is calculated here as the 819 difference between $T_{d}$ and $T_{\text {opt }}$. Scope indicates the percentage of metabolic rates predicted at $T_{d}$ of those predicted at $T_{o p t}$, assuming that $T_{o p t}$ indicates the absolute maximal metabolic capacity of the species.

\begin{tabular}{|c|c|c|c|c|c|c|c|c|c|c|c|}
\hline Family & Species & n & $\begin{array}{l}\text { Mass } \\
\text { (g) }\end{array}$ & $\begin{array}{l}T_{\text {pref }} \\
\left({ }^{\circ} \mathrm{C}\right) \\
\end{array}$ & $\begin{array}{l}\mathrm{CT}_{\max } \\
\left({ }^{\circ} \mathrm{C}\right)\end{array}$ & $\begin{array}{c}T_{d} \\
\left({ }^{\circ} \mathrm{C}\right) \\
\end{array}$ & $\begin{array}{l}T_{\text {opt }} \\
\left({ }^{\circ} \mathrm{C}\right) \\
\end{array}$ & $\begin{array}{l}T_{\max } \\
\left({ }^{\circ} \mathrm{C}\right) \\
\end{array}$ & $\begin{array}{c}\text { Breadth } \\
\left({ }^{\circ} \mathrm{C}\right)\end{array}$ & $\begin{array}{c}\text { Scope } \\
(\%)\end{array}$ & Sources \\
\hline Scincidae & $\begin{array}{l}\text { Tiliqua rugosa } \\
\text { Egernia cunninghamii }\end{array}$ & 105 & 257 & 32.9 & 45.5 & 31.8 & 36.1 & 44.7 & 4.90 & 90.7 & $\begin{array}{l}\text { Warburg (1965); Wilson (1974); } \\
\text { Bennett and John-Alder (1986) } \\
\text { Spellerberg (1972); Wilson } \\
\text { (1974); Bennett and John-Alder } \\
\text { (1986) }\end{array}$ \\
\hline Agamidae & $\begin{array}{l}\text { Pogona barbata } \\
\text { Physignathus leseuri }\end{array}$ & $\begin{array}{l}37 \\
71\end{array}$ & $\begin{array}{l}239 \\
549 \\
\end{array}$ & $\begin{array}{l}33.2 \\
30.1 \\
\end{array}$ & $\begin{array}{c}46.0 \\
- \\
\end{array}$ & $\begin{array}{l}33.0 \\
29.8 \\
\end{array}$ & $\begin{array}{l}36.7 \\
34.0 \\
\end{array}$ & $\begin{array}{l}44.2 \\
42.4 \\
\end{array}$ & $\begin{array}{l}3.74 \\
4.21 \\
\end{array}$ & $\begin{array}{l}90.7 \\
90.7\end{array}$ & $\begin{array}{l}\text { Licht (1965); Warburg (1965); } \\
\text { Schäuble and Grigg (1998) } \\
\text { Wilson (1974) }\end{array}$ \\
\hline Iguanidae & $\begin{array}{l}\text { Sauromalus hispidus } \\
\text { Amblyrhynchus cristatus } \\
\text { Iguana iguana } \\
\text { Dipsosaurus dorsalis }\end{array}$ & 23 & $\begin{array}{l}574 \\
489\end{array}$ & $\begin{array}{l}35.9 \\
33.4\end{array}$ & - & 32.0 & $\begin{array}{l}36.6 \\
37.1\end{array}$ & 43.8 & $\begin{array}{l}4.56 \\
3.35 \\
4.29\end{array}$ & $\begin{array}{l}90.7 \\
90.7 \\
90.7 \\
90.8\end{array}$ & $\begin{array}{l}\text { Bennett (1972) } \\
\text { Wilhoft (1958); Bartholomew } \\
\text { (1966); White (1973) } \\
\text { Moberly (1968); Brusch et al. } \\
\text { (2016) } \\
\text { Licht (1964); DeWitt (1967); } \\
\text { Bennett and Dawson (1972) }\end{array}$ \\
\hline
\end{tabular}


Table 2: Akaike Information Criterion (AIC) comparison of the fitted models characterized according to a candidate set of ten published thermal performance functions. The function with the lowest AIC score, and hence a $\triangle \mathrm{AIC}$ of zero, is deemed to be the most parsimonious model of the candidate set; in this case the beta-distribution function. Canonically, models within two AIC distances are considered statistically indistinguishable from the most parsimonious model (Raftery, 1995), in this case capturing three functions.

\begin{tabular}{|ll|l|l|c|}
\hline \multicolumn{1}{|c|}{ Performance Function } & K & DAIC & Log Likelihood \\
\hline Beta-distribution & (Yan \& Hunt, 1999) & 4 & 0.00 & -252.84 \\
\hline Exponentially-penalized logistic & (Kovac et al., 2007) & 6 & 0.24 & -250.96 \\
\hline Arrhenius & (Sharpe \& DeMichele, 1977) & 7 & 1.31 & -250.41 \\
\hline Skewed normal & (Lehman et al., 1975) & 5 & 3.20 & -253.42 \\
\hline Exponential power & (Lassiter, 1975) & 5 & 4.61 & -254.12 \\
\hline two-way negative exponential & (Huey \& Stevenson, 1979) & 4 & 7.74 & -254.66 \\
\hline Modified cubic & (Knies et al., 2006; Knies et al., 2009) & 4 & 10.03 & -257.85 \\
\hline Biexponential & (Logan et al., 1976; Tomlinson et al., 2015) & 6 & -266.05 \\
\hline Logistic x logistic & (Thornton \& Lessem, 1978) & 5 & 596.62 & -549.15 \\
\hline Special Poisson & (O'Neill et al., 1972) & 6 & 5423.69 & -2963.66 \\
\hline
\end{tabular}


Table 3: Beta functions of thermal performance of maximum metabolic rates for the nine species of reptile investigated.

\begin{tabular}{|c|c|c|}
\hline Family & Species & Performance Function \\
\hline Scincidae & $\begin{array}{l}\text { Tiliqua rugosa } \\
\text { Egernia cunninghamii }\end{array}$ & $\begin{array}{l}1.94 \times\left(\frac{47.1-\mathrm{T}_{\mathrm{b}}}{47.1-37.3}\right) \times\left(\frac{\mathrm{T}_{\mathrm{b}}}{37.3}\right)^{\frac{37.3}{47.37 .3}} \\
1.99 \times\left(\frac{44.7-\mathrm{T}_{\mathrm{b}}}{44.7-36.1}\right) \times\left(\frac{\mathrm{T}_{\mathrm{b}}}{36.1}\right)^{\frac{36.1}{44.7-36.1}}\end{array}$ \\
\hline Agamidae & $\begin{array}{l}\text { Pogona barbata } \\
\text { Physignathus leseuri }\end{array}$ & $\begin{array}{l}2.19 \times\left(\frac{44.2-\mathrm{T}_{\mathrm{b}}}{44.2-36.7}\right) \times\left(\frac{\mathrm{T}_{\mathrm{b}}}{36.7}\right)^{\frac{36.2}{44.36 .7}} \\
1.79 \times\left(\frac{42.4-\mathrm{T}_{\mathrm{b}}}{42.4-34.0}\right) \times\left(\frac{\mathrm{T}_{\mathrm{b}}}{34.0}\right)^{\frac{34.0}{42.4-34.0}}\end{array}$ \\
\hline Iguanidae & $\begin{array}{l}\text { Sauromalus hispidus } \\
\text { Amblyrhynchus cristatus } \\
\text { Iguana iguana } \\
\text { Dipsosaurus dorsalis }\end{array}$ & $\begin{array}{l}2.10 \times\left(\frac{45.7-\mathrm{T}_{\mathrm{b}}}{45.7-36.6}\right) \times\left(\frac{\mathrm{T}_{\mathrm{b}}}{36.6}\right)^{\frac{36.6}{45.7-36.6}} \\
2.89 \times\left(\frac{41.3-\mathrm{T}_{\mathrm{b}}}{41.3-37.1}\right) \times\left(\frac{\mathrm{T}_{\mathrm{b}}}{37.1}\right)^{\frac{37.1}{41.3-37.1}} \\
2.10 \times\left(\frac{46.6-\mathrm{T}_{\mathrm{b}}}{46.6-38.0}\right) \times\left(\frac{\mathrm{T}_{\mathrm{b}}}{38.0}\right)^{\frac{38.0}{46.6-38.0}} \\
5.12 \times\left(\frac{46.7-\mathrm{T}_{\mathrm{b}}}{46.7-41.3}\right) \times\left(\frac{\mathrm{T}_{\mathrm{b}}}{41.3}\right)^{\frac{41.3}{46.7-41.3}}\end{array}$ \\
\hline
\end{tabular}

